\title{
Identification of Critical Control Points in Some Nigerian Fermented Foods and Seasonings
}

\author{
Asagbra A. E., Onawola O. O., Okeagu M.O.
}

\begin{abstract}
Fermented foods constitute a significant component of African diets, some as staple foods while others include weaning foods and condiments. These foods are produced at house hold level and sent to relations abroad, whereas some are produced semi-commercially. In all this, hygiene and packaging are of a major concern. The aim of the study is to identify possible hazards and critical control points (CCPs) in the production of some Nigerian fermented dietary foods in order to help reduce risks to health as a result of the consumption of these foods, as these foods are exported to the diaspora. Three processors from Ijebu town Ogun state in Nigeria were visited and observed on the traditional processing of garri, iru and ogiri respectively. Soy-ogi is a fermented technological product of the Federal Institute of Industrial Research (FIIRO). Potential hazards and critical control points at each step of the process were each identified by the use of a decision tree. In all cases, the major hazards identified were biological. All the raw material, fermentation and drying steps were identified as CCPs. Hazard Analysis Critical Control Points (HACCP) was carried out to teach small and medium scale entrepreneurs who acquire the technology of producing these fermented foods. Prerequisite programmes (environmental sanitation and personal hygiene) are suggested as strategies to improve the safety of these traditional fermented foods and condiments.
\end{abstract}

Index Terms - CCP, Fermentation, Flow diagram, Soy-ogi.

\section{INTRODUCTION}

Highlight Fermented foods are foods that are a product of fermentation processes and they could be of plant or animal origin. They are estimated to contribute about a quarter of the food consumed world-wide [5].Fermented foods constitute a significant component of African diets, some as staple foods while others include weaning foods and condiments,as such, theyplay an important role in the diets in tropical developing countries. Fermentation is an ancient method of food processing aimed at prolonging the shelf-life and palatability of food and in most cases; it does also improve the digestibility and nutritional value of food or feed [8]. The availability of fermentable substrate is the most important driving force for fermentation. However, each type of

\footnotetext{
ASAGBRA A. E., Food Safety \& Quality Management Division, Department of Production, Analytical Services and Laboratory Management, Federal Institute of Industrial Research, Oshodi, Lagos, Nigeria ONAWOLA O. O., Department of Biotechnology, Federal Institute of Industrial Research, Oshodi, Lagos, Nigeria.

OKEAGU M.O, Food Safety \& Quality Management Division, Department of Production, Analytical Services and Laboratory Management, Federal Institute of Industrial Research, Oshodi, Lagos, Nigeria
}

substrate/raw material possesses a unique combination of physical structure, chemical composition and natural microflora which influences the sequence of microbial development and the activity of endogenous enzymes during fermentation [2]. In general, fermented foods in Nigeria can be classified into groups according to the substrates employed and these include products from tubers such as garri, lafun, fufuetc; products from cereals such as ogi, soy-ogi; products from legumes such as iru, ogiriafiyo and soy dawadawa; products from milk such as warankasi, monshanu, yoghurts and beverages such as wines from tropical fruits.

Though fermentation is considered safe and acceptable preservation technology, the failure of the process can result in spoilage and unexpected health risk in food products. Natural vegetable fermentations of roots, cereals and oil seeds undergo successive stages of fermentation including an initiation phase. However, in order to speed up fermentation and increase its predictability, process control is required, and this include choosing pretreatment and incubation conditionsto ensure and maintain the artificial dominanceof starter organisms over epiphytic microorganisms, thereby limiting spoilage and risk of pathogen infestation. As such, the metabolic activities of desirable fermentation microorganisms must be supported by an understanding and the application of Hazard Analysis and Critical Control Points (HACCP) concept [9].The HACCP concept permits a systematic approachto the identification of hazards and an assessment of thelikelihoodof an occurrence during manufacture, distribution and use of a food product, and defines measures for their control. In the concept, the term hazard refers to any agent in, or condition of, food that is unacceptable because it has the potential to cause an adverse health effect. The hazards include pathogenic microorganisms and/or their toxins, chemicals (carcinogens and allergens), and physical objects such as stones, bottles etc that may injure the consumer.

Despite the dawn of science and technology in developing countries, most production of fermented foods may still largely be a traditional family art at home in crude manner. The foods are produced at house hold level and sent to relations abroad, whereas some are produced semi-commercially. In all this, hygiene and presence of chemicals and physical objects are a major concern. Therefore the application of HACCP to food preparation permits the identification of practices that may be potentially hazardous and requires modification or practices that are critical for ensuring the safety of the food and requires specific monitoring [6]. Motarjemi [7]also reported that 
HACCP studies of some fermented products have revealed that depending on the process and hygienic condition during preparation, some fermented foods might still pose a safety risk mainly due to post fermentation contaminations. The assurance that food will not cause harm/injury to the consumer when it is prepared and/or consumed according to intended use is referred to as food safety [16]. It is therefore the aim of the authors to identify possible hazards and CCPs in the production of some Nigerian fermented dietary foods in order to help reduce risks to health as a result of the consumption of these foods as well as to promote both local and international trade relations as some of these foods have been introduced into other parts of the country and some into the Diaspora where they are consumed by some members of the populace therein.

\section{MATERIALS AND METHODS}

\section{A. Materials}

Maize grains (Zeamays), Soybeans grains (Glycine max), Cassava tubers (Manihotesculenta), Melon seeds (Cucumeropsismannii) and African locust bean (Parkiabiglobosa) were all purchased from Agege and Mushin markets respectively in Lagos state, Nigeria.

\section{B. Methods}

Three processors were observed in the traditional processing of garri, iru and ogiri, however, Soy ogi is indigenous to FIIRO.The experiment was carried out at the Federal Institute of Industrial Research.

Preparation of soy-ogi: soy ogiis a cereal product fortified with soybeans to increase its protein content [3].Firstly, both raw materials are prepared separately to an extent before they are then combined and processed into a single product. Ogi is a staple food in many parts of Nigeria and is prepared from fermented maize, sorghum, millet. It also serves in diets for convalescents and as a weaning food for infants. Traditionally, cereal grains e.g. maize are de-stoned and made free of other debris after which they are washed and then soaked in water (steeping) for 1 to 2 days. The grains are then wet-milled and sieved to remove the chaff and other coarse particles. The slurry obtained is left in containers at ambient temperatures for a further 1 to 2 days to allow further fermentation and development of taste and aroma. The spontaneous fermentation of the slurry is dominated by Lactobacillusplantarum. Soya beans grains are obtained,dehulled dry and the hulls aspirated. Thereafter, they are washed, cooked and mill into slurry. To the fermented ogicake is added soya bean cake and these are mixed together until even. The resulting soy-ogi slurry is then dewatered to form a cake which is then dried. After drying, the soy-ogi cake is sieved and blended smooth to obtain the soy-ogi powder and thereafter, it is packaged.

Preparation of garri by the fermentation of cassava roots:garri is a roasted granulated product and is a staple food prepared from the root of the plant (Manihotesculenta). Traditionally, the raw material, cassava is peeled and cut into portions after it is grinded into a pulp/mash. The pulp is kept in an open sack and allowed to stand at ambient temperatures for 3-5 days for fermentation to occur. This is majorly by the action of Corynebacteriummanihort and Geotrichum sp. which ferments the starch, leading to a production of acids and consequently lowering the $\mathrm{pH}$ as well production of the characteristic taste and aroma of garri. At the end of fermentation, the sack is tied and its content dewatered by pressing until dry. The resulting product is sieved and the fine starch particles are roasted in local iron pots which may or may not have been coated with a little palm-oil.

Preparation of iru(dawadawa) by the fermentation of African locust bean: Iru is a popular food condiment common in west and central Africa. It is known as 'Sounbala' in Burkinafaso, Mali 'dawadawa' in northern Nigeria and Ghana and 'iru' in southern Nigeria. It has a pungent odour and is a product of the alkaline fermentations of African locust bean seeds (Parkiabiglobasa). Traditionally, the seeds of the African locust bean plant are sorted, washed and boiled in water for 24 hours (h) or a little bit more until the seed coats are soft. After boiling, the seeds are transferred into a mortar and to it were added abrasive materials such as sand. These are rubbed together in the mortar with the aid of a pestle in order to detach the hard seedcoat from the cotyledons as a procedure for dehulling. The cotyledons are separated from the hulls by washing and straining in water, after which they are boiled for 3 to $4 \mathrm{~h}$. The water is drained and the dehulled seeds are placed in containers laced with and covered with leaves and allowed to ferment for 2 to 4 days at ambient temperatures or near a source of heat to hasten fermentation. After fermentation, the fermented seeds or mash (depending on the period of fermentation) are harvested for sale either in wet form or are dried under the sun for 2 to 3 days (depending on the weather and quantity to be dried) or near heat. Prior to harvesting, the leaves of the palm tree are obtained, burnt to ash and sprinkled on the wet mash to garnish it, thus providing an aesthetic appeal to the consumers. The dominant microorganism involved in fermentation is Bacillus subtilis.

Preparation of ogirifrom melon seeds:Ogiri is a product of the fermentation of boiled melon seeds (Cucumeropsismaniiand other varieties of melon seeds) [12]. It is a food flavouring condiment like iru and is used in sauces and stews and is also added to other preparations as seasoning e.g. in boiled meat and staple foods such as ikokore - a Nigerian local pottage. It is consumed in the Eastern, South-Western and Middle belt regions of Nigeria. The traditional preparation of ogiri from melon seeds involves boiling the raw seeds that had been dehusked, after which they are dehulled (separation of the seed coat of the melon seeds from the cotyledons) manually with the aid of the feet. The cotyledons are separated from the hulls and boiled again to soften seeds for fermentation and thereafter wrapped in leaves and kept in sacks. They are then incubated near earthen pots for a period of three to five days or longer at ambient temperatures. The fermented mash is dried and milled to a smooth paste, the ogiri [12].

C Construction of flow diagrams

A flow diagram of all the processes was carried out and the identification of hazards/ Hazard analysis was done as described by Van Schothorst [14].All raw materials (maize, soya beans, cassava, African locust bean and melon seeds) were reviewed for potential hazards such as wet and mouldy 
grains, presence of weevils and presence of anti-nutritive factors. Processing operations and actual operating practices were also evaluated for other potential hazards such as microbiological, chemical and physical hazards. This is facilitated by the application of a flexible decision tree, which indicates a logical reasoning approach.

The decision tree summary for all the products

- Category and identified hazard: Determine if hazard is fully controlled by adherence to Codex General Principles of Food hygiene. If Yes, indicate "GMPs", describe and proceed to next identified hazard. If No, proceed to question 1 .

- Question 1: Does a control measure(s) exist for the identified hazard? If yes, describe and proceed to the next question. If No, this is not a CCP. Is control at this step necessary for safety? If Yes, identify how the hazard can be controlled before or after the process and proceed to the next identified hazard. (modify step, process or product)

- Question 2: Does this step eliminate or reduce the likely occurrence of a hazard to an acceptable level? If No, proceed to Question 3. If Yes, this is a CCP, identify it as such in the last column.

- Question 3: Could contamination with the identified hazard (s) occur in excess of acceptable level(s) or could it increase to unacceptable level? If No, this is not a CCP. Proceed to the next identified hazard, if Yes, proceed to Question 4.

- Question 4: Will subsequent step eliminate hazard(s) or reduce its likely occurrence to a acceptable level? If No, this is a CCP. Identify it AS SUCH IN THE LAST COLUMN. If Yes this not a CCP. Identify the subsequent step and proceed to the next identified hazard.

DIdentification/Determination of Critical Control Points (CCPs).

This was carried out as described by Van Schothorst [14].

\begin{tabular}{|l|l|l|l|l|l|l|}
\hline $\begin{array}{c}\text { St } \\
\text { ep }\end{array}$ & $\begin{array}{r}\text { rd } \\
\hline\end{array}$ & $\mathbf{1}$ & $\mathbf{2}$ & $\mathbf{3}$ & $\mathbf{4}$ & P? \\
\hline & & & & & & \\
\hline
\end{tabular}

Each step in the food chain/process steps was evaluated for its influence on the product. Each process step was also evaluated for a possible control of one or more factors to prevent or eliminate a food safety hazard (such as pesticides, foreign materials etc.) or reduce it to an acceptable level. Such steps where specific control measures are necessary to remove specifichazard/s or reduce them to acceptable levels, beyond which no further step in the process can remove or reduce, are considered critical and are labeled CCPs. This is also facilitated by the application of a flexible decision tree. Cleaning and disinfection of equipment, process lines and environment are CCPs.
III. RESULTS
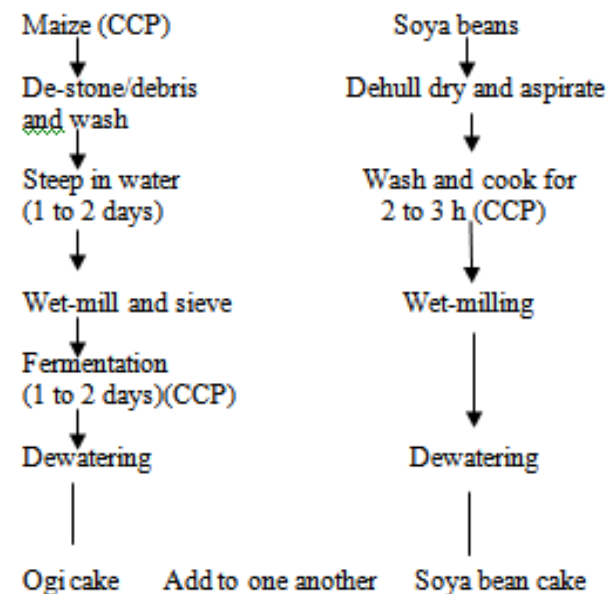

and $\operatorname{mix}$ until even

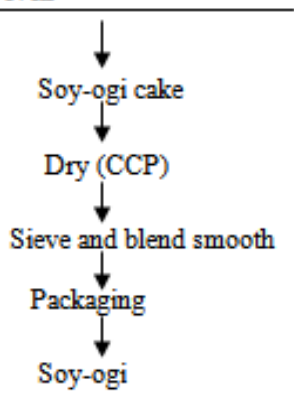

Fig. 1: Flow chart for the preparation of soy-ogi with identified $\mathrm{CCP}$

\section{Cassava tubers $(\mathrm{CCP})$}

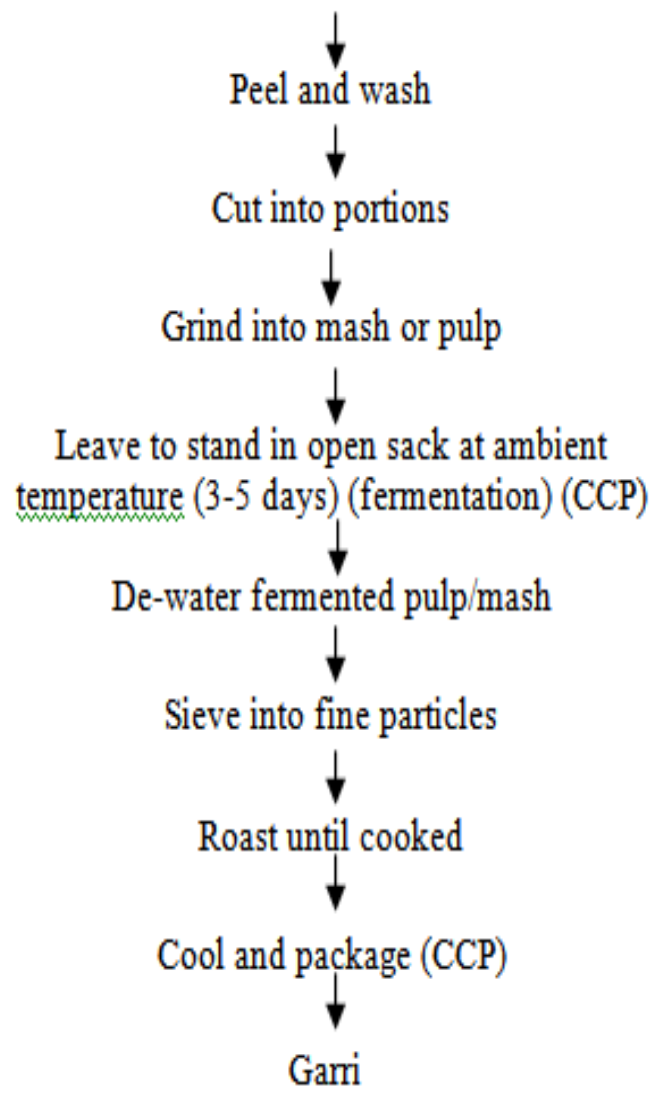

Fig. 2: Flow chart for the preparation of garri with identified CCPs 


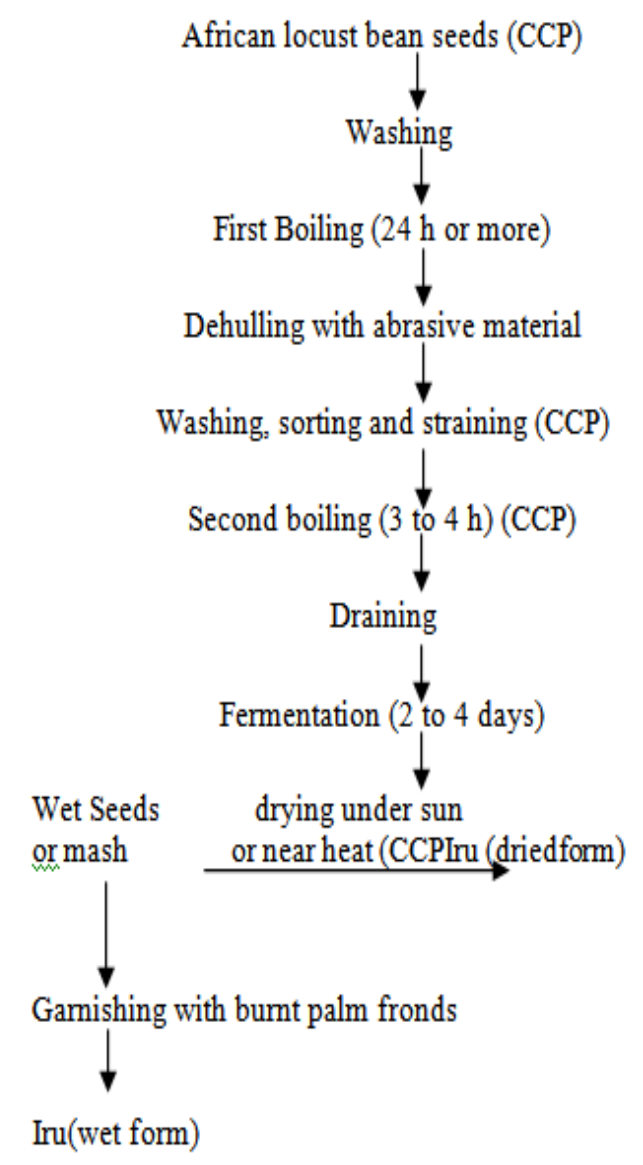

Fig.3 Flow chart for the preparation of Iru with Identified

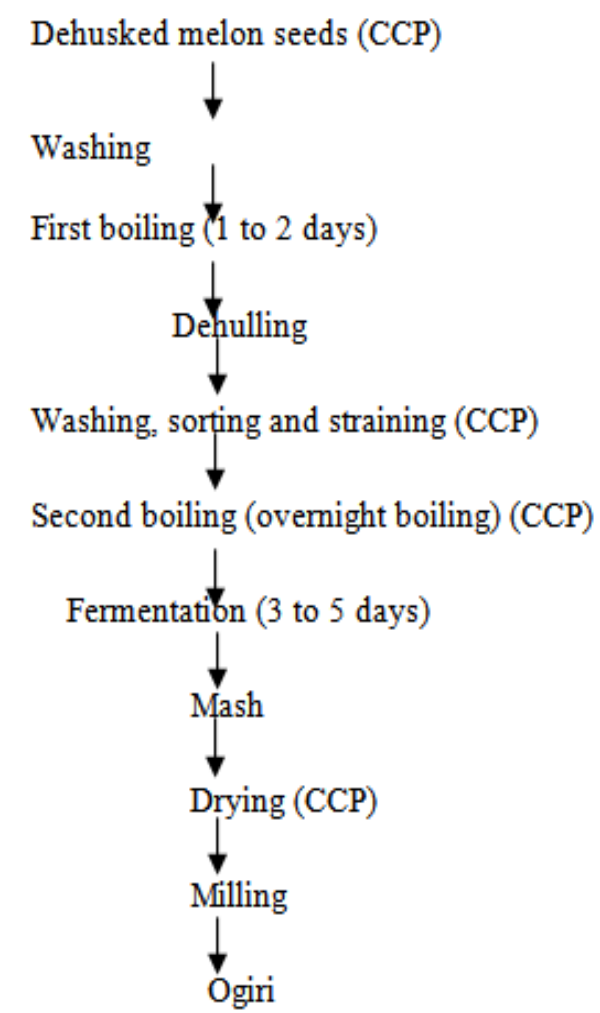

Fig.4 Flow chart for the preparation of ogiri with identified CCPs

\section{DISCUSSION}

Hazards associated with soy-ogi include growth of moulds (particularly mycotoxin-producing species), presence of weevils in maize grains, growth of spoilage and pathogenic microorganisms during processing, presence of anti-nutritive factors in soya beans and high water activity of the product. As such, the CCPs identified in soy-ogiare as presented in fig. 1. Maize presents the major hazard as it is the point where mycotoxins and the grainary weevil Sitophilisgranariuscan be introduced into the food product. These may result into contamination of product if weevil eggs are not destroyed during processing and health risk due to presence of toxins. Anti-nutritive factors such as trypsin inhibitors and phytic acid amongst others are present in soya beans (Glycine max) and these cause flatulence and impair protein digestibility amongst others in monogastrics [17]. The heat-treatment of soya beans eliminates trypsin inhibitors and hydrolyses phytic acid. This step is therefore critical for the removal of these anti-nutritive factors. A high water activity supports growth of microorganisms which could come as spoilage or pathogenic depending on the storage condition with the consumer. The drying step is therefore a CCP for the reduction of moisture in order to control microbial infestation. Control of overall hygiene, good house-keeping and disinfection of the plant is also critical in overall product quality. Hazards associated with garri include growth of microorganisms (particularly toxin-producing species),presence of spoilage and pathogenic microorganisms duringprocessing, presence of anti-nutritive factors such as trypsin inhibitors, phytic acid and cyanogenicglucosidesetcin cassava roots, with high values in the bitter variety[13] and presence of rots on cassava roots. CCPs identified in garri production are as presented in fig. 2. Presence of rots (soft, dry or dark) cassava roots implies tubers are already infested with fungi some of which may be pathogenic [15]. This results into spoilage of product or health risk if these are not totally killed off during the roasting step. It is therefore critical that the cassava roots must remain hard with no presence of softening or rottenness. Fermentation step is not only necessary for digestibility of product and aroma generation, it is aneffective step for the removal of the poison, thecyanogenicglucosides present in roots of bitter cassava. During fermentation, the poison is hydrolysed by the action of fermenting organisms and Abdullahi and Saba [1] reported that the combination of fermentation for 5 days and mechanical pressing (de-watering) of the pulp reduces effectively the cyanide content of the cassava to WHO standard.The fermentation step is clearly a CCP for the removal of the chemical hazard, cyanide which is very lethal. The product (garri) obtained immediately after roasting/frying the fermented and de-watered pulp is hot and humid and if packaged as such, it will result into caking of product and microbial infestation due to the moisture level. To prevent this, a control measure is therefore required since any hazard re-introduced can no longer be corrected. Thus, the cooling and packaging step is a CCP.

Hazards associated with iru include growth of microorganisms (particularly toxin-producing species) which might find entry into the food through the african locust bean 
seeds, growth of spoilage and pathogenic microorganisms during processing, presence of abrasive material employed in the dehulling step, presence of anti-nutritive factors in African locust bean seeds and water activity of the product. CCPs identified in iru production are as presented in fig. 3 . African locust bean seeds present the major hazard as it is the point where mycotoxins can be introduced into the food product. It is also the point where anti-nutritve factors are introduced into the food. The use of dry grains which had not at any time supported the growth of microorganisms is critical in the production of iru as this ensures that adverse microbial infestation is prevented right from the raw material step. It is therefore a CCP.In the dehulling process, abrasive materials such as sand or rice husks are employed in the removal of the softened but clinging seed coat. As such, the parboiled seeds must be made free of this as it is a risk factor for health as well as palatability of the product. It is therefore crucial that the abrasive materials be removed/strained off in the washing and sorting steps as no other step afterwards can remove it. This thus makes the washing and sorting step a point of critical control for the removal of the physical hazard.Oluwaniyi and Bazambo, [11] have reported presence as oxalic acid and phytic acid in raw african locust bean seeds. Oxalic acid and its chelated form can pose health-related hazard. The cooking of the African locust bean seeds for a minimum of $3 \mathrm{~h}$ destroys the heat-labile anti-nutritive phytates present in it, thus making bio-available the chelated micro-nutrients. This also is a CCP as no other step in the process or beyond it will be able to take care of the anti-nutritive factor. In addition to this, the second boiling serves to destroy microorganisms present on seeds after the dehulling and sorting steps and to create favourable condition for the selectionof desirable organisms responsible for the fermentation of the beans through their heat-resistant spores. Oluwaniyi and Bazambo, [11] have also reported the marked reduction in levels of oxalates as a result of fermentation of the seeds. Iru is most often presented and sold as a wet product, due to the wet nature; it can support growth of spoilage microorganisms depending on the storage condition with the consumer. The drying step is a point of control, however, since product is exposed to the sun or near source of heat as a step for preservation,product are exposed to microbial infestationand thiscan result into spoilage or pathogenic microorganisms re-introduction into the product. Microbial infestation can be brought about by the action of insects (flies etc) which are attracted by the pungent odour of iruand rodents (lizards etc) crawling on or have come to feed on the product. In addition, sand and/or other objects might drop unto the wet mash and these are dried and packaged together. Inadequate hygienic conditions during drying transport and storage can result into contamination by molds which in turn can result into formation of mycotoxins [4]. This thus makes the drying step a CCPfor the prevention of re-introduction of both biological and physical hazards. Control of overall hygiene, good house-keeping and disinfection of the plant is also critical in overall product quality.

Hazards associated with ogiri include growth of microorganisms (particularly toxin-producing species) which might find entry into the food through the melon seeds, growth of spoilage and pathogenic microorganisms during processing, presence of husks. CCPs identified in ogiri production are as presented in fig. 4. Melon seeds present the major hazard as it is the point where bacterial and fungal toxins can be introduced into the food product. Elimination of these biological hazards isrequired eliminated right from the raw material step. The raw material selection step is therefore a CCP. The dehulling process is manual and mostly done with the feet by traditional entrepreneurs; this can directly or indirectly introduce sand into the product. Sand is a physical hazard and a health-risk factor, as such, its removal is crucial in the washing and sorting step as no other step beyond sorting can take care of the hazard.This thus makes the washing and sorting step a CCP. The second boiling of melon seeds serves to soften the cotyledons for fermentation and to destroy microorganisms present on seeds after the dehulling and sorting steps in order to help in the selective colonization of desirable organisms responsible for fermentation. This second boiling step is therefore a CCP for the removal of spoilage and pathogenic organisms prior to the fermentation step and for the selection of desirable fermenting organisms. Ogiri is presented and sold as a moisture-free thick paste; as such the drying process is essential. The moisture is reduced by drying in the sun; however wet mashis not protected from infestation by insects and rodents which are attracted due to the pungent odour and possibly need for food during drying the step.This will result into re-introduction of spoilage or pathogenic microorganisms into the product. In addition, sand and/or other objects might drop unto the wet mash and these are dried and milled together. Inadequate hygienic conditions during drying, transport and storage can result into contamination by molds which in turn can result into formation of mycotoxins [4]. This thus makes the drying step a CCP for the control of re-introduction of biological and physical hazards. Control of overall hygiene, good house-keeping and disinfection of the plant is also critical in overall product quality.

\section{ACKNOWLEGMENT}

The authors acknowledge the management of FIIRO for the use of the Pilot Plant in FIIRO.

\section{CONFLICT OF INTEREST}

The authors declare that there is no conflict of interest in the preparation of this paper.

\section{REFERENCES}

[1] M.Abdullahi, and A. M. Saba, "Comparative study of different processing methods for the reduction of cyanide from bitter cassava flour." ChemSearch Journalvol. 5, iss. 1,2014, pp. 1-7.

[2] R. E.Andersson, M. A.Daeshel, and C. E. Eriksson, "Controlled Lactic Acid Fermentation of Vegetables." In: Procedings of the $8^{\text {th }}$ International Biotechnology Symposium, Paris 1988. ed. G.Durand, L.Bobicho, and J. Florent, 1988a. pp 855-868. Paris: Societe Francais de Microbiologie.

[3] A. Y. Asagbra, A. Sunday,W. A.Odunfa, and J. Mogen, HACCP system for African fermented foods: Soy-ogi. World Association of Industrial and Technological Research Organisations.(WAITRO) Taastrup, ISBN: 87-90737-02-41. 1998. 
[4] O. Erkmen and T.F. Bozoglu, "Food Preservation by Reducing Water Activity.” In:Food Microbiology: principles into practice2016. (eds O. Erkmen and T. F. Bozoglu). doi.org/10.1002/9781119237860.ch30

[5] T. H.Gadaga,L. K. Nyanga, and A. N. Mutukumira, "The occurrence, Growth and Control of Pathogens in African Fermented foods."Afri. J. Food, Agri. Nutri. Dev. vol. 4, iss. 12004.

[6] F. K.Kaferstein, Y Motarjemi, and D. W. Bettcher, "Food-borne disease control: A translational challenge."Emerg. Infecti. Disea.vol 3, iss 4, 1997, pp. 250-259.

[7] Y. Motarjemi, "Impact of small-scale fermentation technology on food safety in developing countries."Int. J. Food. Microbio. vol75, 2002, pp. 213-220.

[8] S. A. Odunfa, "African fermented foods" In:Wood, B. J. (ed.) microbiology of fermented foods. Vol 2 Elsevier Applied Science Publishers, London and New York. 1985, pp155-191

[9] F.A. Oguntoyinbo, "Development of Hazard Analysis Critical Control Points (HACCP) and Enhancement of Microbial Safety Quality during Production of Fermented Legume Based Condiments in Nigeria.' Nigerian Food Journalvol 30,iss. 1,2012, pp. 59-66.

[10] O. Onawola, A. Asagbra, M. Faderin,Comparative Soluble Nutrient Value of Ogiri Obtained from Dehulled and Undehulled Boiled melon Seeds (Cucumeropsismannii).J. Food Science and Quality Managementvol 4, 2012, pp.2224 - 6088 (paper), 2225 - 0557(online)

[11] O. O. Oluwaniyi, and I. O. Bazambo, "Antinutritional and phytochemical evaluation of raw and fermented African locust bean (Parkiabiglobosa) seeds."Global journal of pure and applied sciences. vol 20, 2014,105-109.

[12] O. O. Onawola,A. E.Asagbra,S. O. Akinola and O. O. Olatunji,"Soluble nutrient production during the fermentation of three melon varieties in the leaves of Musa spp. Thaumatococcusdanielli and Carica papaya."Nigerian Food Journalvol 29iss 1, 2011,pp. 12-18.

[13] S. Sarkiyayi, and T. M.Agar, "Comparative analysis on the nutritiona and anti-nutritional contents of the sweet and bitter cassava varieties."Advance journal of food science and technology vol 2 iss 6 , 2010, pp. 328-334.

[14] M.Van Schothorst, "A simple guide to understanding and applying the hazard analysis critical control point concept."International Life Sciences Institute $3^{\text {rd }}$ ed. Europe. ISBN 1-57881-179-1, 2004.

[15] S. A.Vilas Boas, S. A.Santos de Oliveira, C. A.DoreaBraganca,J. B. Ramos, and E. Jorge de Oliveira, "Survey of fungi associated with cassava root rot from different producing regions in Brazil." Sci. Agric. vol 74 iss 1, 2017, pp.60-67. Doi/10./1590/0103-9016-2015-0336

[16] WHO, "HACCP principles and practice: Teacher's handbook. AWHO/ICD training manual in collaboration with FAO.' WHO/SDE/PHE/FOS/99.3, 1999.

[17] R. Yasothai, "Antinutritional factors in soybean meal and its deactivation."International journal of science, environment and technology vol 5, iss 6, 2016, pp. 3793-3797.

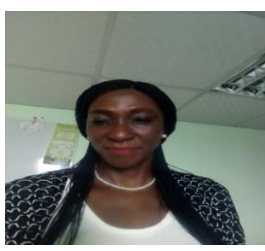

Dr Agnes Yemisi Asagbra is a Microbiologist and a Research Director in the Department of Production, Analytical and Laboratory Management (PALM) of the Federal Institute of Industrial Research Oshodi (FIIRO), Lagos, Nigeria.

She obtained her Bachelor of Science degree with honours in biology from the

University

of Lagos in 1983 , a Master of Science degree in the food and industrial Microbiology in the year 1987 from the University of Benin, Nigeria and a Doctorate in the food and industrial Microbiology from the University of Ibadan.

She holds professional certificates in Quality management systems (ISO 9001: 2015) and Food Safety Management System (ISO22000. 2017). An ISO 9001: 2015 and ISO22000: 2017 auditor.

She has successfully upgraded the local technology for the production of Kunun-zaki (a fermented beverage) and ogiri (condiment) by the application of the concept of Hazard Analysis and Critical Control Points (HACCP).

She is a trainer of FIIRO technology trainees and SME's on

HACCP. She has worked on alcoholic, antibiotic and solid- state fermentations to mention a few.

She holds membership positions in the Nigerian society for Microbiology, Association of industrial
Microbiologists of Nigeria, Nigerian institute of food science and technology (a Fellow) and the Institute of Public Analysts of Nigeria.

She has twenty-six (26) peer reviewed journal publications in both local and international journals and twenty (20) conference proceedings to her credit. She loves reading and travelling.

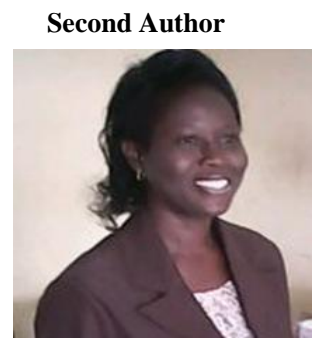

Ms Oluwabukola Oluwatoyin Onawola is a Biochemist and a Principal Research Officer in the Department of Biotechnology of the Federal Institute of Industrial Research Oshodi (FIIRO), Lagos, Nigeria.

She obtained her Bachelor of Science degree with honours in biochemistry from the University of Ilorin in 1992 and a Master of Science degree in the same field in the year 2010 from the University of Lagos, Nigeria respectively. She is currently on her $\mathrm{PhD}$ program at the University of Lagos. She holds professional certificates in Master of Business Administration from the University of Ilorin and in Food Safety Management Systems (Management of Microbiological Hazards in Foods) which she obtained from the Wageningen University of Research, The Netherlands in collaboration with Bells University of Technology, Ota 2013.

She has successfully upgraded the local technology for the production of ogiri (a food condiment) by the application of the concept of Hazard Analysis and Critical Control Points. (2008). She is also an awardee of the grant given by West African Agricultural Project (WAAP) NCRP-Product Development Proposals for the project "Production of high quality phytase from local substrates for application in animal feed" (2010) amongst others.

She holds membership positions in the Nigerian society of biochemistry and molecular biology, Nigerian institute of food science and technology and the Association of industrial microbiologists of Nigeria respectively. She has eight (8) peer reviewed journal publications in both local and international journals and five conference proceedings to her credit.

MsOnawola has interests in reading, organizing events, animal husbandry and tailoring.

\section{Third Author}

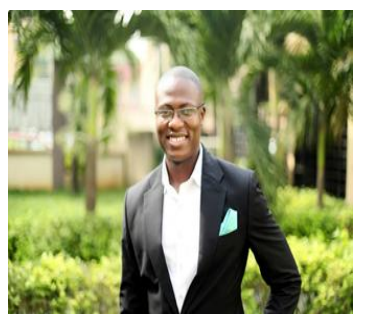

Mr. Okeagu, Martin Okechukwu is a Parasitologist and a Research Officer in the Department of Production, Analytical and Laboratory Management (PALM) of the Federal Institute of Industrial Research Oshodi (FIIRO), Lagos, Nigeria.

He obtained his Bachelor of Science degree with honours in Zoology from the Ahmadu Bello University, Zaria in 2009, a Master of Science degree in Medical Parasitology in the year 2013 from the University of Lagos (UNILAG). He is currently on his PhD program at the University of Lagos with a focus on Parasite Diversity of Amphibians and their Bioindicator Potentials.

He holds professional certificates in Hazard Analysis and Critical Control Points (HACCP) and trains FIIRO technology trainees and SME's on HACCP. He is currently the P.I of the project "Local Production Microbiological Agar from Seaweeds" and a task force member of many ongoing projects at the department.

He holds membership positions with the Parasitology and Public Health Society of Nigeria (PPSN) and the American Society of Tropical Medicine and Hygiene (ASTMH).

He loves reading, playing chess and listening to good music 